\title{
A Figura do Intelectual e a Razão Universal na Fundação do Instituto Histórico e Geográfico Brasileiro
}

\author{
Sérgio Campos Gonçalves. ${ }^{1}$
}

O Instituto Historico e Geographico Brazileiro é o representante das idéas de IIIustração, que em differentes épocas se manifestaram em o nosso continente.

Visconde de São Leopoldo (Pinheiro, 1839)

\section{Introdução}

Em sua batalha contra uma filosofia da mobilidade, da mudança e da fluidez do mundo moderno, sobretudo baseada em ideias bergsonianos, Julien Benda (1867-1956) advogava a manutenção atemporal dos valores universais da razão, sobre os quais repousaria a unidade da humanidade. Tais valores formavam o núcleo de sua compreensão prescritiva da figura do intelectual, tributária de uma moral iluminista, que associa as noções de progresso e de verdade ao papel esclarecedor do agente de letras:

Considero que a humanidade compreende duas espécies de homens, cujas funções são antitéticas, mas de cuja combinação deriva, entretanto, a civilização: os primeiros criam as instituições em detrimento da moral, os segundos pregam a moral em detrimento das instituições; os primeiros são fundadores de impérios, os segundos são clérigos; se não

\footnotetext{
${ }^{1}$ Visiting Researcher na Stanford University (Division of Literature, Cultures and Languages - Iberian and Latin American Cultures) e Doutorando em História e Cultura Social na Universidade Estadual Paulista "Júlio de Mesquita Filho" (UNESP) com bolsa PDSE-CAPES.
} 
existissem no mundo mais que os primeiros, a humanidade progrediria, mas não haveria nada além de barbárie; se não existissem mais do que os segundos, a humanidade seria moral, mas não progrediria (Benda, 1946, p. 115-116. Apud Bobbio, 1997, p.50).

Assim, para Benda, o intelectual desempenharia um papel determinante pelo equilíbrio da civilização, assunto frequentemente em pauta após a Primeira Guerra Mundial. De fato, o capítulo da história das ideias acerca do conceito de civilização revela que a supremacia do paradigma civilizatório ocidental, que moldara a visão de mundo dos europeus e exercera grande influência sobre os povos ligados à matriz filosófica europeia, entrou em crise na primeira metade do século $X X$, a partir das duas grandes guerras mundiais, da grande depressão nos EUA e do Holocausto. Esses eventos colocaram em xeque a fundamentação do modelo ocidental-europeu enquanto referência para alcançar a civilização, o progresso e o desenvolvimento. ${ }^{2}$ Nesse contexto - classificado por Norberto Bobbio como um triunfo do irracionalismo - , Benda permaneceu agarrado à tradição clássica do racionalismo ocidental, à custa de parecer anacrônico, diante do declínio da fé oitocentista na ciência, das filosofias positivistas e materialistas (Bobbio, 1997, p.54). Para Benda (1999), o intelectual verdadeiro deveria ser o porta-voz dos valores universais e eternos do espírito humano, enquanto que o intelectual moderno seria traidor de sua função por aderir aos interesses das contingências nacionalistas e por colocar as paixões temporais acima dos bens espirituais.

\footnotetext{
${ }^{2}$ Sobre a concepção da supremacia do paradigma civilizatório ocidental, ver Fluthy, 1961, p. 483-495; Iggers, 1965; Allardyce, 1982; Nisbet, 1985; Shweder, 2002, p. 117-121 e Bowden, 2009.
} 
Apesar da frequente crítica de que seu idealismo era sem sentido no mundo urbanizado e industrializado e que ignorava as pressões políticas e econômicas causadas pelas transformações estruturais da sociedade de moderna, a obra de Benda tornou-se referência tanto para o estudo das representações da figura do intelectual quanto no próprio meio intelectual para justificar seus modos de participação política, pois, notadamente a partir do caso Dreyfus e do contexto de crise do ideal civilizatório do Ocidente, a tese de Benda comporta uma preocupação própria do mundo intelectual: a questão da independência e do distanciamento entre o pensamento e as suas formas de apropriação pela política (Cf. Winock, 2000, p. 248-256).

Tal questão, no entanto, não se colocava desse modo no século XIX, no auge da justificativa do colonialismo europeu pela ideia da missão civilizatória do Ocidente. Nesse contexto, a figura social do intelectual não participava de uma tensão entre ação e valores do homem político, de Estado, e ação e valores do sábio-pensador, pois, ao contrário, o discurso de ambos frequentemente se legitimava nas determinações universais da razão e em uma filosofia teleológica da história que compreendia a inevitabilidade do tempo rumo ao progresso. Mesmo quando falava por e pela nação, o significado da figura do sábio, do homem de letras e de Estado definia-se a partir da moral racionalista-iluminista e em nome da civilização. Assim como para o intelectual verdadeiro de Benda, antes da crise de legitimidade do colonialismo moderno e da queda da conviçcão da missão civilizatória européia, a figura social do sábio/pensador/ilustrado - hoje , o intelectual - possuía um papel de porta-voz da razão e dos valores da humanidade universal (Bobbio, 1997, p. 141-174). A partir dessas referências - e amparado na noção de elite como grupo detentor de um certo poder e/ou como produto de uma seleção social (Lalquette, 2006, p. 55-74) - , este artigo busca evidenciar a relação entre a política cultural do Estado imperial no Brasil e o perfil do 
grupo de letrados responsável pela fundação do Instituto e Histórico e Geográfico Brasileiro (IHGB) e de sua Revista. ${ }^{3}$

O IHGB foi um palco privilegiado da política cultural do Império no século XIX. Enquanto os fundadores do Instituto participavam da rede de sociabilidades na qual se consolidava a posição dos homens de Estado que orbitavam a Corte, sob seus holofotes, se promulgou a versão oficial da trajetória histórica do Brasil nas páginas de sua Revista. Este capítulo apresenta um estudo sobre a articulação da biografia coletiva dos fundadores do IHGB e de sua Revista com a política cultural do Estado imperial brasileiro, em que se observa, sobretudo, como o perfil dos membros do Instituto conformava determinada figura de intelectual através de sua rede de sociabilidades, sua mentalidade civilizatória e a cultura política de sua geração. Não se trata, contudo, de uma abordagem prosopográfica dos itinerários atenta às sensibilidades subjetivas individuais e nem de tentar alcançar as genealogias de influência através de um mapa dos grandes eixos de engajamento político. Apesar de atento à recomendação de JeanFrançois Sirinelli (2003) de buscar um meio-termo entre a acepção sociocultural ampla do intelectual e a organização de seu grupo "em torno de uma sensibilidade ideológica ou cultural comum e de afinidades mais difusas, mas igualmente determinantes", este artigo procura dar conta de uma microanálise do grupo social que apreende os espaços e os mecanismos de poder envolvidos com a figura de intelectual da época, para, com isso, evidenciar que o significado do intelectual no contexto da fundação do IHGB se definia através de um discurso que une a fala em nome da razão, da humanidade e da civilização, à fala em nome do Estado e da nação.

\footnotetext{
${ }^{3}$ Sobre a noção de elite cultural, ver Sirinelli, 1998. Cf. Bourdieu, 1998.
}

Brasiliana - Journal for Brazilian Studies. Vol. 2, n.1 (March. 2013). ISSN 2245-4373. 


\section{Política cultural e elite intelectual}

A ideia de civilização aportou no Brasil, sobretudo, quando a família real portuguesa exilou-se no Rio de Janeiro com sua Corte em 1808. Juntamente com todos os instrumentos burocráticos, administrativos e de ordenamento jurídico, a família real de D. João VI trouxe sua concepção de mundo e seu aparato de poder institucional e simbólico. Como decorrência, a política cultural joanina serviu-se fartamente dos ícones de civilização para legitimar-se e para tentar forçar a aproximação do Brasil com o padrão civilizatório europeu. ${ }^{4}$ Os esforços por transformações civilizadoras que aconteceram no Rio de Janeiro com D. João VI não mudaram substancialmente seu rumo com as vicissitudes que vieram a seguir. Ao contrário, já no reinado de D. Pedro I há o aprofundamento e a expansão daqueles empreendimentos iniciados no período joanino. Do mesmo modo, com o início da Regência a partir de 1831, e, igualmente, com o Segundo Reinado após 1840, "essa marcha das luzes e do progresso [...] em pouco, ou quase nada, mudará seus rumos", conforme destaca Jean Marcel Carvalho França (1999, p. 4142). Nesse longo período que vai até o final do Império, argumenta França, o que efetivamente teria ocorrido foi “a consolidação de um processo cujas linhas mestras são a urbanização da cidade e a europeização de sua população", as quais, para os contemporâneos, representavam aproximar-se dos estágios mais avançados de civilização (Cf. Bosi, 1975; Cândido, 2000).

Na cidade do Rio de Janeiro, o processo de urbanização foi fundamental para que os hábitos e costumes da sociedade fluminense herdados do isolamento colonial fossem confrontados com a pretensão cosmopolita dos ideais de civilização e progresso. Com a autonomia política do país e com a intensificação da participação da elite cortesã no

\footnotetext{
${ }^{4}$ Ver Malerba, 2000, p. 126 e Schwarcz, 2002, p. 256-332.
} 
Estado, a intelligentsia imperial preocupa-se em conceber no Brasil a nação que se queria construir. Independente desde 1822, restava ao Brasil adquirir uma estrutura cultural própria, estabelecendo uma literatura, uma geografia e, especialmente, uma história. Nesse contexto, segundo França (1999, p. 82), a elite cortesã imperial envolvida com a fundação da ideia de nação aspirava à criação "de uma comunidade de valores apta a gerar no brasileiro o sentimento de pátria" com vistas a "formar o povo", para "torná-lo esclarecido, ordeiro e trabalhador o suficiente para que pudesse colaborar mais decisivamente para o progresso do país". Isso foi evidente na fundação de diversas instituições, como a Sociedade Auxiliadora da Indústria Nacional, o Real Colégio Pedro II e o Instituto Histórico e Geográfico Brasileiro, a agremiação mais significativa entre os intelectuais brasileiros do século XIX. ${ }^{5}$

A compreensão do perfil dos intelectuais reunidos em torno da Revista do IHGB passa, antes de tudo, pelos elementos unificadores de grupo, isto é, para compreender a estrutura dos membros fundadores, sua biografia coletiva, é preciso observar a formação de tais intelectuais através de sua procedência educacional e social e relacionála com suas funções políticas (Ferreira, 2004). Afinal, conforme ilustrou José Murilo de Carvalho (1996, p. 38), apesar de suas rixas e interesses diversos, tal grupo de intelectuais - essa "ilha de letrados num mar de analfabetos" - partilhava de valores e de uma linguagem comuns. Isso teria contribuído para que houvesse um acordo básico sobre a estrutura política e social no processo de formação do Estado, pois os grupos dominantes teriam desenvolvido uma capacidade de processar conflitos em respeito à estabilidade das bases do sistema imperial.

\footnotetext{
5 "É facto que tanto o Colégio Pedro II quanto o Instituto atingiram apenas uma pequena parte da população carioca e menor ainda da população brasileira. Todavia, os poucos indivíduos que puderam ocupar os bancos do primeiro ou folhear as páginas do bulletin do segundo eram aqueles que estavam, ou viriam a estar, no controlo do leme político e cultural do país; eram, em suma, os homens que definiam os rumos da jovem nação" (França, 1999, p. 95). Cf. Neves, 1999.
} 
Apesar dos inevitáveis conflitos envolvidos na formação do Estado na primeira metade do século XIX, havia, para Carvalho, uma "unificação ideológica da política imperial" entre os indivíduos da Corte. A educação superior teria sido um elemento importante de afinidade, em primeiro lugar, porque quase toda a elite possuía estudos superiores, o que acontecia com pouca gente fora dela; em segundo lugar, porque a elite do império partilhava de um núcleo homogêneo de conhecimentos e habilidades, em consequência de sua educação superior se concentrar na formação jurídica; e em terceiro lugar, porque a educação superior se concentrou na Universidade de Coimbra até a Independência - depois dela, a formação intelectual da elite letrada se concentrou em quatro capitais provinciais, ou duas, se considerarmos apenas a formação jurídica. Carvalho (1996, p. 55) compreende que a concentração geográfica promovia contatos pessoais entre estudantes das várias capitanias e províncias e incutia neles uma "ideologia homogênea dentro do estrito controle que as escolas superiores eram submetidas pelos governos tanto de Portugal como do Brasil".

Além disso, a elite política envolvida com o poder imperial desde a Independência apresentava, segundo Carvalho (1996, p. 210), “características básicas de unidade ideológica e de treinamento" oriundas da política de formação de elites do Estado português. Desde o início, portanto, apresentavam sua vocação para a participação na Corte. Não é por acaso que o núcleo dessa elite cortesã fosse formada por burocratas, notadamente por magistrados "treinados nas tradições do mercantilismo e absolutismo portugueses". Conforme assinala Carvalho, a educação em Coimbra, a influência do direito romano, a ocupação burocrática e os mecanismos de treinamento contribuíam para dar à elite que esteve à frente da consolidação do Estado imperial um consenso básico em torno de algumas opções políticas fundamentais. 
A procedência educacional em torno da Universidade de Coimbra esteve ao centro da formação de várias gerações da elite do Império Brasileiro, dos anos 1820 até, pelo menos, o fim da década de 1850, a partir da qual houve um aumento da diversificação da economia e o surgimento de novas atrações de carreira. Realizada por Roderick e Jean Barman (1976), a análise prosopográfica do primeiro círculo de sociabilidade do Império, formado por Família Imperial, Conselho de Estado, Senado e Conselho de Ministros, e de seu segundo escalão, formado por Câmara dos Deputados, Alto Comando do Exército e da Marinha e Supremo Tribunal de Justiça, sustenta que a figura do intelectual do Império foi determinado pela posse do título acadêmico, pela figura do homem letrado, do bacharel. É nessa elite política cortesã envolvida com a política imperial que se observa a estrutura do grupo que fundou o IHGB.

A política cultural do Império, da qual o IHGB fez parte, foi importante para que houvesse uma mínima coerência de idéias sobre a nação e de Estado que se queria elaborar. Agregados ao objetivo da pesquisa histórica, que, segundo o secretário Januário da Cunha Babosa (1839, p. 9), visava a "eternisar pela historia os factos memoraveis da patria", outros fins também interessavam ao IHGB. Conforme Arno Wehling (1983, p. 11) analisou, tais propósitos incluíam “o 'esclarecimento' da sociedade, pelo desenvolvimento da 'cultura literária', levando a um aprimoramento das relações sociais; o aperfeiçoamento da administração pública, com a formação de melhores quadros funcionais; e o exercício mais aperfeiçoado de cargos eletivos". Essa concepção da ação pedagógica e civilizadora da História sobre a política e a administração pública é evidente no "Relatório do Secretário Perpétuo" apresentado durante a "Segunda Sessão Publica Anniversaria" do IHGB, em 27 de novembro de 1840: 
Da ignorancia dos povos vem commummente a facilidade com que se deixão embair. [...] Até o mesmo homem de genio necessita do fio da Historia para se guiar com segurança no obscuro dedalo da politica. [...] A Historia, tornando-lhe presente a experiencia dos seculos passados, ministra-lhe conselhos tão seguros como desinteressados, que lhe aclarão os caminhos que deve seguir, os escolhos que deve evitar, e o seguro porto, a que uma sabia manobra póde felizmente fazer chegar a nau do Estado (Barbosa, 1840, passim). ${ }^{6}$

\section{Intelligentsia imperial e cultura política}

A elite política e intelectual envolvida com o projeto historiográfico do IHGB representava, em geral, os grupos políticos moderados que eram partidários da monarquia constitucional, os quais buscavam impor um projeto político centralizador às demais regiões do país a partir de 1854. Conforme observa Wehling (1983, p. 11), estes integrantes do "partido do regresso, da ordem ou (depois) conservador", avessos ao absolutismo e contrários ao liberalismo radical e ao republicanismo do Período Regencial, teriam reagido às forças centrífugas regionais insubmissas ao poder central do Império que ameaçavam a monarquia constitucional não apenas em sua constituição política, mas também "em seus desdobramentos econômicos, políticos, sociais e ideológicos - liberalismo, grande propriedade, escravidão, padroado, voto censitário".

Naquele momento conturbado, a fundação do IHGB em 1838 pode ser compreendida como uma forma de reação em favor da monarquia constitucional, dado

\footnotetext{
${ }^{6}$ Tal idéia é algo generalizado no IHGB e está largamente disseminada nas páginas da Revista do Instituto, tanto em atas de sessões quanto em vários textos de vários autores. Para alguns dos mais representativos, ver Porto Alegre, 184; Coutinho, 1840; Castilho, 1848; Pinheiro, 1839.
} 
que, em larga medida, significou a criação de um instrumento institucional para a elite cortesã tentar direcionar o futuro do Estado brasileiro. De acordo com Wehling (1983, p. 12), tratava-se de um esforço emanado do Rio de Janeiro para encaminhar politicamente o Brasil, assegurando os interesses dos cafeicultores escravistas do centro-sul, e, ao mesmo tempo, para enfrentar o que lhes parecia "federalismo excessivo (com o eventual desmembramento do país) e ameaça à estabilidade social (oposição à escravidão)" ${ }^{7}$

Wehling (1983, p. 15-16) fornece uma síntese precisa a respeito da determinação política da fundação do IHGB: o Instituto originou-se "da afirmação de uma elite política ideologicamente moderada (no sentido dos anos 30 do século XIX)"․ A recusa desta elite ao republicanismo - "sinônimo, para o grupo, de anarquia e fragmentação" e ao absolutismo - resquício do "partido português" - , para Wehling, "encaminha-a para a solução monárquico-constitucional, desde que escoimada das concessões liberais e regionais do Ato Adicional". A elite letrada fluminense fez da monarquia constitucional uma solução centralizadora, pois, além de significar o controle político provincial, também garantia a conservação de seus próprios fundamentos: "grande propriedade, escravidão, sufrágio censitário, padroado". Wehling observa que todos estes temas, quando surgiram nas páginas da Revista do IHGB em meados do século XIX, foram tratados de um ponto de vista "moderado". Do mesmo modo que, quando alguns deles foram declaradamente combatidos, como a escravidão, "a crítica supõe sempre uma solução evolutiva e não (como o liberalismo radical) de ruptura". Quanto ao plano do pensamento político e histórico, Wehling explica que à perspectiva explícita do nacionalismo romântico somou-se a concepção histórico-filosófica do historicismo: “o estudo da história permite a melhor compreensão do presente e o delineamento do

\footnotetext{
7 "Sob esse ângulo compreende-se melhor por que partiu da Sociedade Auxiliadora da Indústria Nacional - núcleo importante da nascente cafeicultura fluminense, que tanto dependia da escravidão - a proposta de fundação do Instituto" (Wehling, 1983, p. 12).
}

Brasiliana - Journal for Brazilian Studies. Vol. 2, n.1 (March. 2013). ISSN 2245-4373. 
futuro". Neste aspecto, os fundadores do Instituto também teriam se filiado ao liberalismo, conforme definido no século XVIII: "um meio-termo "modernizador" ou "burguês" (conforme a definição teórica do historiador) entre o absolutismo (com os privilégios da sociedade de ordens) e a democracia (com o igualitarismo dos jacobinos)".

Por conseguinte, a construção do IHGB está profundamente ligada ao perfil social dos seus membros e à posição destes na configuração social da sociedade de corte imperial. Os sócios fundadores do Instituto encontravam-se em uma "ilha de letrados", todos viviam na capital do Império, eram vinculados ao Estado monárquico, conviviam na Corte e idealizavam um Brasil que deveria obedecer aos preceitos da civilização ocidental e europeia.

Quadro n 1 - Fundadores do IHGB: perfil sócio-profissional

\begin{tabular}{|c|c|c|c|c|c|}
\hline Fundadores & Naturalidade & Escolaridade & Formação & Ocupação & $\begin{array}{l}\text { Origem sócio- } \\
\text { econômica }\end{array}$ \\
\hline $\begin{array}{l}\text { Alexandre Maria de Mariz } \\
\text { Sarmento }\end{array}$ & Portugal & N. Médio & Aulas Régias & Político & Pai: F. Público \\
\hline Antônio Alves da Silva Pinto & S/ informação & N. Superior & Direito / Coimbra & Advogado & S/ informação \\
\hline $\begin{array}{l}\text { Antônio José de Paiva Guedes } \\
\text { de Andrada }\end{array}$ & S/ informação & S/ informação & S/ informação & F. público & S/ informação \\
\hline $\begin{array}{l}\text { Aureliano de Souza e Oliveira } \\
\text { Coutinho }\end{array}$ & $\mathrm{BR} / \mathrm{RJ}$ & N. Superior & Direito / Coimbra & Político & Pai: Militar \\
\hline Bento da Silva Lisboa & $\mathrm{BR} / \mathrm{BA}$ & N. Médio & Aulas Régias & Político & Pai: F. Público \\
\hline Caetano Maria Lopes Gama & $\mathrm{BR} / \mathrm{PE}$ & N. Superior & Direito / Coimbra & Político & Pai: F. Público \\
\hline Cândido José de Araújo Viana & $\mathrm{BR} / \mathrm{MG}$ & N. Superior & Direito / Coimbra & Político & Pai: Militar \\
\hline Conrado Jacob de Niemeyer & Portugal & N. Superior & $\begin{array}{l}\text { Escola Militar / } \\
\text { Lisboa }\end{array}$ & Militar & Pai: Militar \\
\hline Emílio Joaquim da Silva Maia & $\mathrm{BR} / \mathrm{RJ}$ & N. Superior & Medicina / Paris & Médico & S/ informação \\
\hline $\begin{array}{l}\text { Francisco Cordeiro da Silva } \\
\text { Torres Alvim }\end{array}$ & Portugal & N. Superior & A. Marinha / Lisboa & Político & Pai: Militar \\
\hline
\end{tabular}




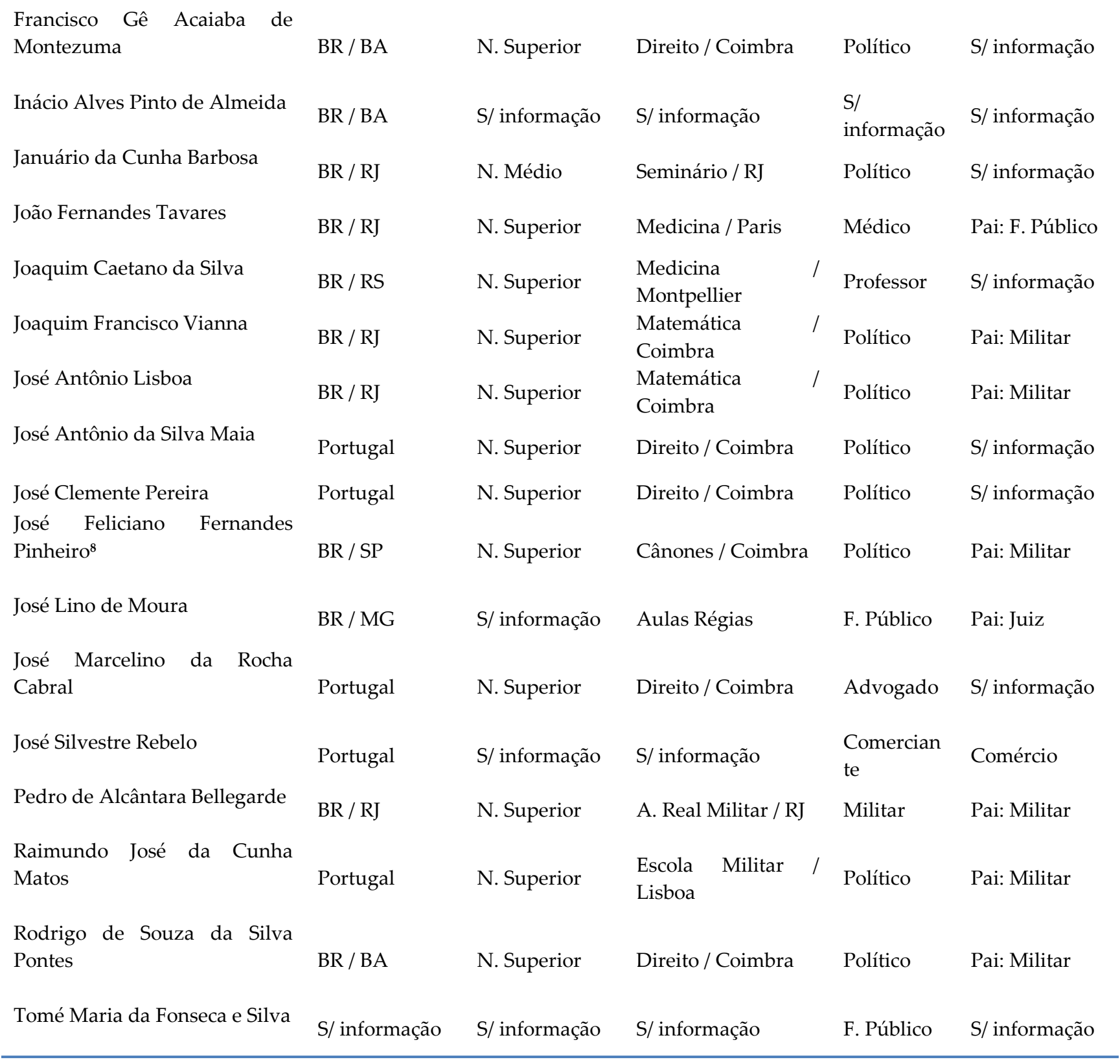

Fonte: Guimarães, 1999, p. 39.

\footnotetext{
${ }^{\mathbf{8}}$ Visconde de São Leopoldo.
}

Brasiliana - Journal for Brazilian Studies. Vol. 2, n.1 (March. 2013). ISSN 2245-4373. 
O quadro dos 27 fundadores do IHGB revela uma relação entre a procedência social, a homogeneidade cultural e ideológica dos seus membros e a vocação da historiografia produzida pelo Instituto para endossar a política cultural e civilizatória que emanava da monarquia brasileira. Neste seleto grupo, predominavam indivíduos de origem urbana, descendentes de militares e funcionários públicos que fizeram a Independência e que adotaram a monarquia para dar forma ao país. Viviam no centro do establishment imperial, a Corte, e formavam a "ilha de letrados" que esteve à frente da literatura e das artes palacianas. ${ }^{9}$ De acordo Lúcia M. Paschoal Guimarães (1999, p. 42), “daqueles segmentos da sociedade luso-brasileira, saíram os homens públicos que dirigiram o país até meados do século XIX. Esses mesmos vultos estiveram à testa do Instituto Histórico". Na prática, a direta participação do alto escalão do Estado monárquico gerava um reconhecimento institucionalizado da Revista do IHGB como instrumento legítimo de expressão historiográfica. Conforme atesta Bourdieu (1996, p. 133), “as produções simbólicas devem suas propriedades mais específicas às suas condições sociais de sua produção e, mais precisamente, à posição do produtor no campo de produção". ${ }^{10}$

Entre esses homens públicos, tal qual observou Arno Wehling (1999, p. 36), “a heterogeneidade funcional era compensada pela unidade ideológica", pois quase todos

\footnotetext{
${ }^{9}$ Para acompanhar a história do IHGB em seus pormenores burocráticos e administrativos, ver Fazenda, 1911.

10 "A especificidade do discurso de autoridade [...] reside no fato de que não basta que ele seja compreendido [...], é preciso que ele seja reconhecido enquanto tal para que possa exercer seu efeito próprio. Tal reconhecimento [...] somente tem lugar como se fora algo evidente sob determinadas condições, as mesmas que definem seu uso legítimo: tal uso deve ser pronunciado pela pessoa autorizada a fazê-lo, [...] deve ser pronunciado numa situação legítima, ou seja, perante os receptores legítimos [...], devendo enfim ser enunciado nas formas [...] legítimas. As chamadas condições litúrgicas, ou seja, o conjunto das prescrições que regem a forma da manifestação pública de autoridade, a etiqueta das cerimônias, o código dos gestos e o ordenamento oficial dos ritos, constituem apenas o elemento mais visível de um sistema de condições, as mais importantes e insubstituíveis das quais são as que produzem a disposição ao reconhecimento como crença e desconhecimento, vale dizer, a delegação da autoridade que confere sua autoridade ao discurso autorizado" (Bourdieu, 1996, p. 91).
}

Brasiliana - Journal for Brazilian Studies. Vol. 2, n.1 (March. 2013). ISSN 2245-4373. 
os fundadores do IHGB eram indivíduos de visão nacionalista e centralizadora. De acordo com Wehling (1994, p. 155), a ação política dessa elite política "regressista" tendia a reforçar a autoridade central e a garantir a monarquia constitucional: "reação às revoltas regionais, Lei Interpretativa do Ato Adicional, reforma do Código de Processo Criminal". A fundação do Instituto inserir-se-ia neste processo e, por essa razão, os textos publicados na Revista do IHGB são muito claros na defesa da Monarquia constitucional e do sistema unitário como regime político ideal para o país. Membros da elite política do Império, os fundadores do IHGB professavam os mesmos ideais: nas palavras de Wehling (1994, p. 155), “a defesa da unidade nacional, consolidação do governo civil, redução do conflito em nível nacional, limitação da mobilidade social e da mobilização política...". ${ }^{11}$

Assim, havia uma cultura política compartilhada pelo grupo de intelectuais fundadores do IHGB, para o qual a Monarquia constitucional configurava como um importante fator de coesão para seu projeto de Estado e de futuro para o Brasil. Isto é, seu perfil professava uma espécie de um código e um conjunto de referentes formalizado tanto no jogo interno da política nacional quanto em uma tradição política mais abrangente, da monarquia. ${ }^{12}$

\section{Estado imperial e etiqueta cortesã}

Os fundadores do IHGB eram notórios homens públicos, mas o vínculo quase visceral entre os interesses do Estado e a produção historiográfica ia além de uma simples presença de burocratas de alto escalão nos quadros institucionais, pois o Estado

\footnotetext{
${ }^{11}$ Ver Barbosa, 1839.

12 Sobre o estudo do intelectual enquanto fenômeno individual e coletivo da cultura política, ver Berstein, 1998.
}

Brasiliana - Journal for Brazilian Studies. Vol. 2, n.1 (March. 2013). ISSN 2245-4373. 
monárquico usufruiu da elaboração de um discurso histórico legitimador de seus interesses (Cf. Guimarães, 1995, p. 514-515). Por um lado, o IHGB nutriu-se do dinheiro imperial para sustentar suas atividades, tanto que, cinco anos após sua fundação, as verbas do Estado já representavam $75 \%$ de seu orçamento. ${ }^{13}$ Por outro, integrou uma “política de memória nacional”, que, segundo Arno Wehling (1999, p. 33-35), envolveu três frentes. Enquanto a primeira diz respeito ao plano literário, profundamente ligado ao establishment regressista, comprometido com a "busca da identidade nacional" através do romantismo, as demais se apresentaram a partir da ação direta do poder público: a fundação do Colégio Pedro II e do Arquivo Nacional, instituições que visavam à consolidação da educação, da cultura e da administração pública; e a criação do IHGB, através da Sociedade Auxiliadora da Indústria Nacional, o qual enunciava abertamente suas finalidades científicas, culturais, educacionais e administrativas. Com isso, é compreensível que houvesse uma expressiva afinidade entre os interesses do Estado imperial que se firmava, o projeto historiográfico do IHGB e o perfil social, político e profissional dos membros do Instituto. Não surpreende, portanto, que nos primeiros anos da Revista do IHGB houvesse a defesa dos mesmos pontos fundamentais:

a monarquia constitucional e a unidade do país; uma estrutura política centralizada compatibilizada com as descentralização administrativa; afirmação do Poder Moderador e do Conselho de Estado; o abolicionismo gradual; o sistema representativo; a subordinação da

\footnotetext{
13 “Cinco anos após a sua fundação, as verbas do Estado Imperial já representavam 75\% do orçamento do IHGB, porcentagem que tendeu a se manter constante ao longo do século XIX. Tendo em vista que, para a realização de seus projetos especiais, tais como viagens exploratórias, pesquisas e coletas de material em arquivos estrangeiros, o IHGB se via obrigado a recorrer ao Estado com o pedido de verbas extras, pode-se avaliar como decisiva a ajuda do Estado para sua existência material” (Guimarães, 1988, p. 9). Cf. Diehl, 1998, p. 28.
} 
igualdade à liberdade, "aceitando desigualdades funcionais"; as liberdades concretas viabilizadas pelas instituições; e o reforço do poder, para assegurar as liberdades contra o mandonismo local.

O exemplo do Instituto Histórico e Geográfico Brasileiro é a mais concreta realização, no plano cultural, deste objetivo (Wehling, 1999, p. 34-35).

A articulação entre o projeto político-cultural do Império e os intelectuais do IHGB está evidente desde suas primeiras publicações, nas quais se buscava legitimar historicamente os primeiros passos independentes do Brasil frente ao seu passado colonial - o qual Sérgio Buarque de Holanda (1985, p. 9-39) chamou de "desagregador". ${ }^{14}$

A cultura política dos homens de letras que fundaram o IHGB transparece também nos Juízos sobre a publicação ou não de textos na Revista do Instituto, dado que os critérios muitas vezes passavam do plano acadêmico para o político. Isso é explícito no Juizo sobre a "Historia do Brazil", publicada em Paris pelo Sr. Dr. Francisco Solano Constâncio, assinado pelos membros Cândido José de Araújo Vianna e Rodrigo de Sousa da Silva Pontes, no qual os pareceristas condenavam a obra de Constâncio por seu posicionamento sobre a Independência do Brasil:

A primeira reflexão, que ocorre ao leitor Brazileiro é a do manifesto doloroso sentimento de despeito, que acompanha sempre o autor pela emancipação das antigas colonias de Portugal na America. Elle tem na verdade sempre á mão um insulto, uma calumnia, um convicio, para

\footnotetext{
${ }^{14}$ Ver também Guimarães, 1995, p. 515-516.
} 
lançar em rosto á maior parte dos homens, que prestaram serviços á Independencia do Imperio, que mostraram sympathia por essa justissima causa, ou que não fizeram correr ondas de sangue d'aquelles, que desejavam sacudir o jugo da mãe-patria. A um lançará a pecha de fanfarrão, e inhabil, a outro a de astuto, e perfido; este será, na polida phrase do nosso historiador, inimigo declarado dos Portuguezes, e um dos mais astutos, e perfidos facciosos, aquelle um general desleal, est'outro um almirante traidor. As personagens de jerarchia, a mais elevada, não se acham fóra do alcance das settas do Sr. Dr. Constancio. O Sr. D. Pedro I é por longo tempo o alvo de seus tiros. O primeiro Imperador do Brazil tinha abraçado cordialmente a causa da lndependencia: e por isso conforme as expressões do autor tinha indignamente trahido, e vilipendiado a nação Portugueza (Viana, 1839, p. 83).

O Juizo publicado com a chancela do IHGB avisava que "as noticias geographicas do Brazil, offerecidas a seus leitores pelo Sr. Dr. Constancio, difficilmente poderão predispôr a alguem para encetar a leitura da historia confiado na veracidade, e na imparcialidade do historiador". Dizia o parecer que o leitor sensato e versado nas coisas da sua pátria devia estar preparado, pois "sensações desagradaveis, e afflictivas hão de succeder-se-lhe umas após de outras". Assim se resumia o parecer da obra de Constâncio: "alteração da verdade historica, injustiça para com os homens, e politica absolutamente errada, são as qualidades mais preeminentes do historiador, a que ora se applica o escalpello da critica" (Viana, 1839, p. 82).

O critério político também está presente no juízo de Bento da Silva Lisboa e de José Domingues de Ataíde Moncorvo sobre a Histoire des rélations commerciales entre la 
France et le Brésil, de Horace Say. Novamente, os pareceristas demonstram-se descontentes com o posicionamento político do autor e a forma como ele descreveu os acontecimentos da Independência:

A commissão não póde tambem deixar de declarar que o Sr. Horacio Say, além de ser summamente injusto na idéa que fórma do caracter do Sr. D. João VI, e do Imperador D. Pedro I, parece contradictorio, quando louva ao primeiro pela abertura dos portos do Brazil a todas as nações pela carta regia de 28 de Janeiro de 1808, que justamente chama decreto simples, mas que por si só continha uma revolução, por acabar com o systema colonial, e fazer a independencia do Brazil; e ao segundo, por se ter identificado com Brazileiros, pondo-se á testa da sua independencia, e prestando-lhe mui relevantes serviços (Lisboa; Moncorvo, 1839, p. 252).

Em contrapartida, os pareceres publicados na Revista do IHGB emitiram juízos elogiosos às obras que se mostravam alinhadas com as ideias do projeto político dos homens de Estado imperial. Ao tratar da Voyage pittoresque et historique au Brésil, ou Séjour d'um artiste français au Bresil, depuis 1816 jusqu'em 1831 inclusivement, do prestigiado Jean-Baptiste Debret, os mesmos pareceristas, Bento da Silva Lisboa e José Domingues de Ataíde Moncorvo, celebraram as opiniões do autor em acordo com o ideal civilizatório que a elite letrada fluminense tinha como referência para a construção do Estado e da nação no Brasil: 
A Commissão viu com muita satisfação o elogio que o auctor faz aos seus discipulos brasileiros, que fizeram taes progressos em seis annos, que muitos d'elles foram empregados como professores nas escolas de pintura, e contribuindo por isso para que elle podesse voltar apara a França, a fim de cuidar da impressão da 1. a parte da sua obra. Igual satisfação experimenta a Comissão, quando o auctor diz que o Brasil vae desenvolvendo progressivamente uma civilisação que honra muito ao povo que o habita, o qual é dotado das qualidades as mais preciosas (Lisboa; Moncorvo, 1841, p. 96).

Além da situação na qual pareceristas e autores compartilhavam da mesma posição e opinião políticas, os elogios também convinham de acordo com o prestígio do autor da obra em avaliação. Embora os pareceristas Gustavo Adolfo de Aguilar Pantoja, Cândido José de Araújo Viana e Rodrigo de Sousa da Silva Pontes (1840, p. 254) tenham se mostrado tão atentos aos detalhes da obra de Antonio Ladislau Monteiro Baena, um membro correspondente do Instituto, chegando a apontar que o "deffeito capital" da obra avaliada [...] "está no methodo, ou antes na falta de methodo, com que foi escripta a obra do Sr. Baena", os mesmos pareceristas esquivaram-se de fazer uma análise profunda da obra de José Feliciano Fernandes Pinheiro, o Visconde de São Leopoldo, primeiro presidente do IHGB então em exercício:

Difficil e penoso encargo é sem duvida o de examinar e censurar, quando se trata de pessoa munida com titulos correntes, e legalisados para exigir de seus pretendidos censores a mais cabal homenagem de consideração e respeito, dado que esses mesmos não sejam 
espontaneamente os primeiros a fazer justiça ao varão benemerito da sua patria. Difficil é na verdade a posição de censores taes que desapprovando podem ver-se recusados por menos competentes na materia sujeita do que o escriptor censurado, ao mesmo passo que approvando nada podem accrescentar ao bem adquirido renome do sabio elogiado. Tal é porém, senhores, a posição em que se acha collocada a commissão de historia por vós incumbida de examinar e censurar a nova edição dos Annaes da provincia do Rio Grande do Sul, excellente producção do nosso illustre presidente o $\mathrm{IIl}^{\mathrm{mo}}$ e Ex ${ }^{\mathrm{mo}}$ Sr. visconde de S. Leopoldo. A commissão desistiria certamente de tal empreza se a necessidade de obedecer-vos não fosse superior a todas e quaesquer outras considerações; e tão sómente no presupposto de cumprir da maneira possivel com o preceito do Instituto, passa desde já a entrar no assumpto (Pantoja; Viana; Pontes, 1839, p. 255-256).

Ao contrário dos pareceres que tratam de obras de homens de fora do círculo da elite imperial e do IHGB, não há um único confronto com os dados apresentados pelo Visconde, nenhum argumento dele é colocado em discussão. Os pareceristas limitam-se a reportar ao leitor que Fernandes Pinheiro fez determinada descrição topográfica em sua obra, mas jamais ousam contrastar os dados apresentados como geralmente fizeram em outros Juizos publicados na Revista do IHGB. ${ }^{15}$

A construção da memória do Império nas páginas da Revista do IHGB e o estoque do material que deveria ser historicamente lembrado, de acordo com Lúcia M. Paschoal Guimarães, foram orientados pelas condições nas quais os grupos políticos

\footnotetext{
${ }^{\mathbf{1 5}}$ Ver também Rebelo, 1840 e Varnhagen, 1844.
} 
bem relacionados com o IHGB dialogaram com as circunstâncias históricas em que estavam envolvidos. Desse modo, "graças a uma militância intelectual homogênea, marcada pela fidelidade ao imperador", observa Lúcia Guimarães (1995, p. 599), a prática historiográfica do IHGB visou a sustentar o projeto político da Monarquia imperial centralizadora e constitucional.

A submissão às normas de etiqueta política do espaço de sociabilidade da Corte não é aleatória. A figura do intelectual na Monarquia brasileira envolvido com a fundação do IHGB, assim como a autorização do que poderia ser publicado nas páginas da Revista do Instituto, situava-se na rede de conexões e interdependências da configuração social do Império. ${ }^{16}$

\section{Intelectual patriota e civilizador}

A análise do perfil dos sócios do IHGB revela um vínculo irrefutável com a hierarquia interna do Estado. Mas seu exame mostra, também, que a forma da organização do quadro social do Instituto formava, nas palavras de Lilia Moritz Schwarcz (1993, p. 102), "um conjunto que mais se assemelhava a uma sociedade de corte". ${ }^{17}$ A "ilha de letrados" a partir da qual se definia a figura do intelectual vinculado ao Estado imperial estava ao centro da teia das relações sociais que circunscreviam o IHGB, cujo padrão da organização hierárquica, sobretudo a partir de 1849, é análogo ao de uma sociedade de

\footnotetext{
16 “Não é possível compreender uma trajetória (...) sem que tenhamos previamente construído os estados sucessivos do campo no qual ela se desenrolou e, logo, no conjunto das relações objetivas que uniram o agente considerado (...) ao conjunto dos outros agentes envolvidos no mesmo campo e confrontados com o mesmo espaço dos possíveis" (Bourdieu, 1998, p. 190).

${ }^{17}$ Veja também a análise da hierarquia interna do IHGB e de seus critérios de admissão característicos da "sociedade de corte" entre as páginas 101 e 108.
} 
corte. Nessa esteira, Manuel Luiz Salgado Guimarães também atesta que o IHGB era marcado por critérios que presidiam e organizavam “um tipo de sociabilização própria da sociedade de corte". Por isso, sua produção historiográfica estava apoiada na teia das relações sociais e pessoais da Corte, dado que, "enquanto na Europa o processo de escrita e disciplinarização da história estava se efetuando fundamentalmente no espaço universitário”, segundo Manuel L. S. Guimarães (1988, p. 9), “entre nós esta tarefa ficará ainda zelosamente preservada dentro dos muros da academia de tipo ilustrado, de acesso restrito, regulamentado por critérios que passam necessariamente pela teia das relações sociais e pessoais". Para Guimarães, o Estado desempenhou um papel marcante ao se pensar a construção da história nacional, pois atuou "como eixo central a partir do qual se lê a história do Brasil, produzida nos círculos restritos da elite letrada imperial".

Não é por acaso que entre os nomes presentes no Instituto havia dez conselheiros de Estado, seis dos quais senadores. Reunindo a nata da política imperial, a intelligentsia cortesã defensora da Casa de Bragança, através de seu desejo de fundar uma historiografia nacional e original, atuava no IHGB, nas palavras de Lília Schwarcz (1993, p. 102), com “a intenção não só de ensinar e divulgar conhecimentos, mas também com o desejo de formular uma história que, a exemplo dos demais modelos europeus, se dedicasse à exaltação e glória da pátria". Envolvidos com a política cultural do Império e protagonistas de sua prática historiográfico-discursiva, os intelectuais fundadores do IHGB não possuíam um perfil aleatório. Formavam uma combinação de políticos, literatos e funcionários públicos que gravitavam ao redor do trono na sociedade de corte fluminense. Seu interesse no controle da produção historiográfica evidenciava o propósito de se consagrar como a elite central no cenário nacional, diante das forças contrárias à cristalização do poder centralizado da monarquia no Rio de Janeiro e em sua Corte. Para isso, edificaram um discurso que associava a fundação do IHGB à 
realização da razão universal, da civilização ocidental e européia, para legitimar o arranjo político do poder imperial.

No período pós-Independência, a geração romântica patrioticamente empregou na história uma lógica comemorativa do estandarte nacional. Essa elite política, "ideológica e esteticamente nacionalista e, com freqüência, romântica", nas palavras de Arno Wehling, tinha o objetivo de consolidar o ideal nacional através da reconstituição da História pátria, pois "os documentos dos anos iniciais do Instituto Histórico e Geográfico Brasileiro demonstraram, pelas idéias expostas e pelos autores mencionados, a forte influência do romantismo europeu, particularmente o francês". Wehling explica que "romantismo e nacionalismo entrelaçam-se com bastante naturalidade, na Europa como no Império nascente". Os fundadores do Instituto objetivaram reconstituir a História pátria para consolidar o ideal nacional, mas como não dispunham de um passado medieval, recorreram à temática indígena. Muito antes do indianismo literário de Gonçalves Dias ou Alencar, observa Wehling, há um "indianismo erudito" nas páginas da Revista do IHGB: “a partir de 1839, quando são estudados guaicurus, tupinambás e outras tribos na perspectiva etnológica ou na de sua incorporação ao processo civilizatório". A idealização do passado histórico brasileiro, de suas riquezas naturais e de suas potencialidades, encontrado desde as primeiras páginas da Revista do IHGB denuncia que a fórmula nacionalista-romântica encontrou terreno fértil entre os intelectuais brasileiros no século XIX. ${ }^{18}$ Em que pese a tensão permanente entre "a valorização da cultura nacional e o padrão universal do naturalismo racionalista", os

\footnotetext{
${ }^{18}$ Wehling (1999, p. 37) explica que tal fórmula nacionalista-romântica não ficou isenta de contradições quando transposta e aplicada deste lado do Atlântico: "inspirada em ideologias européias, criticava historiadores não portugueses que, como Southey, estudaram a História do Brasil; veementemente antilusitana e anticolonial, elogiava a obra apologética de Rocha Pita sobre a América portuguesa; crítica do 'obscurantismo cultural' praticado por Portugal no Brasil até o século XVIII, considerava como antecessor 'ilustrado' do Instituto o academicismo que floresceu a sombra dos governadores coloniais e vice-reis".
}

Brasiliana - Journal for Brazilian Studies. Vol. 2, n.1 (March. 2013). ISSN 2245-4373. 
membros do IHGB acreditavam que o "gênio da história" servia ao "progresso da humanidade"; segundo Wehling (1999, p. 36-39), os estudos históricos eram vistos no Instituto Histórico "como instrumentos de aperfeiçoamento institucional para esclarecimento dos titulares de cargos eletivos, que deveriam aprimorar a representação e elevar o nível de consciência política dos representados". A exaltação romântica do patriotismo é evidente no discurso oficial do orador Manoel de Araujo Porto-Alegre, na sexta sessão comemorativa do aniversário do IHGB:

A patria, Senhores, é a segunda placenta do homem adulto: sem o seu influxo moral não ha virtudes, não ha heroismo, não ha o bello, não ha o sublime: o povo que antecipa a prevenção ao juizo, o ridículo á critica, o sarcasmo á razão, a inveja á gloria, e a indifferença ao enthusiasmo, é uma tribu que caminha com passos gigantescos para a escravidão, tão desgraçado e tão cego que fora melhor não existir (Porto Alegre, 1848, p. 226).

No IHGB, como na historiografia ocidental oitocentista em geral, consolidou-se a versão nacionalista e romântica do historicismo. O Instituto Histórico articulou as noções de Estado e Civilização em sua prática discursiva-historiográfica para explicar o movimento temporal das culturas, situando-as em uma dinâmica social teleologicamente orientada na qual o ápice estava o modelo europeu, em especial França e Inglaterra. Conforme compreende Wehling (1999, p. 42), "mais do que o romantismo e o nacionalismo no plano ideológico", essa "lógica da história" teve o historicismo como o plano teóricometodológico que deu forma e racionalizou a cosmovisão dos fundadores do IHGB. Tal "lógica" compunha uma "história tríplice", a mesma dos historiadores de desde o final 
do século XVIII: filosófica, que fornecesse uma interpretação do significado dos acontecimentos à luz das grandes tendências; pragmática, que fosse uma referência de orientação para a sociedade; e crítica, que apresentasse a verdade objetiva através de métodos confiáveis, em que pese a possibilidade de distorções políticas, religiosas e de excessos literários.

Juntamente com tal "lógica da história", composta por esse plano teóricometodológico do historicismo e pela crença na função pedagógica do conhecimento histórico, a articulação do IHGB e de seus membros com os interesses da Monarquia constitucional centralizada na Corte fluminense fez nascer uma historiografia que produziu uma leitura específica do Brasil, limitada pelas fronteiras do Estado Nacional e pelo jogo das relações sociais de sua sociedade de corte. A leitura da história empreendida pelo IHGB, segundo Manuel L. S. Guimarães (1988, p. 8), buscou “dar conta da gênese da Nação brasileira, inserindo-a contudo numa tradição de civilização e progresso, ideias tão caras ao iluminismo". Assim, o retrato do Brasil que o Instituto Histórico se propôs a traçar tratava de colocar o surgimento da Nação como "o desdobramento, nos trópicos, de uma civilização branca e europeia".

Enquanto conhecimento aplicado, a História desempenhava uma função pragmática, pedagógica, - aquela mesma da concepção clássica imortalizada no epíteto de Cícero, "história, mestra da vida": a História deveria didaticamente mostrar o caminho da ação e tornar claros os erros do passado. ${ }^{19}$ A concepção de História compartilhada pelos membros do Instituto Histórico era muito próxima àquela verificada no Instituto Histórico de Paris, para o qual caberia à História regenerar

19 "La expresión historia magistra vitae fue acuñada por Cicerón, apoyándose en ejemplos helenísticos. Se encuentra en el contexto de la retórica: sólo el orador sería capaz de conferir inmortalidad a la vida de las Historien instructivas, de hacer perenne su tesoro de experiencia. [...] La tarea rectora que Cicerón adjudica al arte de la historia está presuntamente orientada a la praxis en la que está inmerso el orador" (Koselleck, 1993, p. 44).

Brasiliana - Journal for Brazilian Studies. Vol. 2, n.1 (March. 2013). ISSN 2245-4373. 
pacificamente o corpo social, afirmando seu presente nacional e educando-o a partir dos exemplos do passado. Fundamental, o conhecimento da História seria capaz de fornecer a orientação para materializar o desenvolvimento civilizatório. Essa formulação é exemplar no discurso que Januário da Cunha Barbosa proferiu aos associados do Instituto na sua Segunda Sessão Aniversária:

A política, e a civilisação em geral, exigem que nos appliquemos a salvar da voracidade dos séculos os factos, que nos conduzírão ao estado presente da nossa moralidade, e que sirvão nos tempos futuros de comparação com os nossos progressos, depois de constituidos em nação independente. Testemunha dos tempos, luz da verdade, ella [a História] abunda de elementos necessarios á nossa civilisação, e á prosperidade do Estado; mestra da vida, offerece exemplares de heroicos feitos aos que prezão a honra de servir a Patria, e de viver além da sepultura pela recordação de gloriosas acções (Barbosa, 1840, p. 587).

De acordo com Manuel L. S. Guimarães (2002, p. 196-197), “era preciso ver na História um ensinamento moral e a importância dos fatos narrados estava justamente na possibilidade de se extrair deles uma lição, constituí-los em fonte de exemplos, inspiração para o patriotismo". ${ }^{20}$

Os intelectuais fundadores do Instituto Histórico proclamavam carregar essa tarefa patriótica: responsabilizavam-se por domesticar os fragmentos do passado nacional, imprimindo neles um sentido histórico que fornecesse explicações históricas

\footnotetext{
${ }^{20}$ Cf. Malerba, 2007, p. 351-370.
} 
para as demandas da realidade do presente e que, também, ensinasse o Brasil a alcançar os mesmos progressos materiais de que a Europa civilizada desfrutava.

\section{Considerações Finais}

A rede de sociabilidades dos homens de letras, sua mentalidade civilizatória e a cultura política monarquista e constitucional de sua geração evidenciam que a figura do intelectual fundador do IHGB e de sua Revista situa-se em outro tempo e em outro lugar em relação à dicotomia de Julien Benda entre o intelectual verdadeiro e o intelectual moderno-traidor. Para a elite cortesã do Império do Brasil no século XIX, não haveria uma separação, como para Benda, entre o intelectual verdadeiro, que coloca seu pensamento a serviço da razão universal da humanidade, e o intelectual modernotraidor, que coloca seu pensamento a serviço dos interesses temporais do Estado e da nação. Muito pelo contrário, o significado do intelectual no contexto da fundação do IHGB se define justamente através de um discurso que une a fala em nome da razão, da humanidade e da civilização, à fala em nome do Estado e da nação. Unificada por uma mesma leitura de passado e perspectiva de futuro, sujeita à mesma etiqueta moral de mentalidade civilizatória e aos valores de uma cultura política monarquista, a intelligentsia da elite cortesã imperial fundou a Revista do IHGB como uma realização da razão, da civilização ocidental e europeia, para legitimar o arranjo político do poder do Estado monárquico brasileiro.

\section{Referências Bibliográficas}


ALLARDYCE, G. The Rise and Fall of the Western Civilization Course. The American Historical Review, Vol. 87, No. 3 (Jun., 1982), pp. 695-725. Disponível em: http://www.jstor.org/stable/1864161 Acesso em: 23/11/2009 13:30.

BARBOSA, Januário da Cunha. Discurso recitado no acto de estatuir-se o Instituto Historico e Geographico Brazileiro. Revista do IHGB. 1:9-18, 1839.

BARBOSA, Januário da Cunha. Relatório do Secretário Perpétuo. Segunda Sessão Pública Anniversaria do Instituto Histórico e Geographico Brasileiro. Revista do IHGB. 1840, tomo 2 (supplemento): 582-603.

BARMAN, Roderick; BARMAN, Jean. The Role of the Law Graduate in the Political Elite of Imperial Brazil. Journal of Interamerican Studies and World Affairs, Vol. 18, No. 4 (Nov., 1976), pp. 423-450. Disponível em: Acesso em: 01/05/2011.

BENDA, Julien. A traição dos intelectuais. In: BASTOS, Elide Rugai; RÊGO, Walquíria D. Leão. Intelectuais e política: a moralidade do compromisso. São Paulo: Olho d'Água, 1999. BENDA, Julien. Exercise d'um enterre vif. Paris: Gallimard, 1946.

BERSTEIN, Serge. A cultura política. In: RIOUX, Jean-Pierre; SIRINELLI, Jean-François. Para uma história cultural. Lisboa: Estampa, 1998, p. 349-363.

BOBBIO, Norberto. Os Intelectuais e o Poder. São Paulo: Editora UNESP, 1997.

BOSI, Alfredo. História concisa da literatura brasileira. São Paulo: Cultrix, 1975.

BOURDIEU, Pierre. A economia das trocas lingüísticas: o que falar quer dizer. São Paulo: Ed. da Universidade de São Paulo, 1996.

BOURDIEU, Pierre. A ilusão biográfica. In: FERREIRA, Marieta de Moraes; AMADO, Janaína. Usos e abusos da História Oral. 2a ed. Rio de Janeiro: Editora FGV, 1998, p. 183191.

BOURDIEU, Pierre. Campo del poder, campo intellectual y habitus de clase. In: Intelectuales, política y poder. Buenos Aires: Eudeba, 2000. 
BOWDEN, B. The empire of civilization: the evolution of an imperial idea. Chicago; London: The Chicago University Press, 2009.

CÂNDIDO, Antônio. Literatura e sociedade. São Paulo: T. A. Queiroz; Publifolha, 2000. CARVALHO, José Murilo de. A construção da ordem: a elite política imperial; Teatro de sombras: a política imperial. - 2ª ed. - Rio de Janeiro: Editora UFRJ, Relume-Dumará, 1996.

CASTILHO, José Feliciano de. Discurso sobre a necessidade de se protegerem as ciências, as letras e as artes no Império do Brasil. Revista do IHGB. 11:259-266,1848; 2.ed. 259-266

COUTINHO, Aureliano de Souza e Oliveira. Discurso d'abertura recitado pelo VicePresidente o Exm. Sr. Aureliano de Souza e Oliveira Coutinho, no dia 27 de Novembro de 1840. Segunda Sessão Pública Anniversaria do Instituto Histórico e Geographico Brasileiro. Revista do IHGB. 1840, tomo 2 (supplemento): 574-582

CRESPO, Regina. Las revistas y suplementos culturales como objetos de investigación. Coloquio Internacional de Historia y Ciencias Sociales. Colima, Universidad de Colima, 2010, Publicación en CD-ROM.

DIEHL, Astor Antônio. A cultura historiográfica brasileira: do IHGB aos anos 1930. Passo Fundo: Ediupf, 1998.

FAZENDA, José Vieira. Instituto Historico e Geographico Brazileiro, subsídios para sua História (1838-1911), pelo Dr. José Vieira Fazenda (Bibliothecario do Instituto). Revista do IHGB. T. 74, v. 124, p. 277-439, 1911.

FERREIRA, Tânia Maria Tavares Bessone da Cruz. História e prosopografia. In: _; TAVARES, Célia Cristina da Silva (Orgs.). Anais do X Encontro Regional de História ANPUH-RJ, 2002, Rio de Janeiro. História e Biografias. Rio de Janeiro: UERJ, 2004. 
FLUTHY, H. Colonization and the Making of Mankind. The Journal of Economic History, Vol. 21, No. 4 (Dec., 1961), pp. 483-495. Disponível em: http://www.jstor.org/stable/2114413 Acesso em: 25/03/2009 16:08.

FRANÇA, Jean Marcel Carvalho. Literatura e sociedade no Rio de Janeiro oitocentista. Lisboa: Imprensa Nacional; Casa da Moeda, 1999.

GRILLO, María del Carmen. El studio de revistas como objeto historiográfico para la historia de las redes intelectuales. Coloquio Internacional de Historia y Ciencias Sociales. Colima, Universidad de Colima, 2010, Publicación en CD-ROM.

GUIMARÃES, Lúcia Maria Paschoal. "O tribunal da posteridade". In: PRADO, Emilia Prado. (Org.). O Estado como vocação: idéias e práticas políticas no Brasil oitocentista. Rio de Janeiro: Acess, 1999.

GUIMARÃES, Lúcia Maria Paschoal. Debaixo da imediata proteção imperial: o Instituto Histórico e Geográfico Brasileiro, 1838-1889. Revista do IHGB. 156(388), jul./set. 1995.

GUIMARÃES, Manuel Luiz Salgado. Entre o amadorismo e o profissionalismo: as tensões da prática histórica no século XIX. Topoi. Rio de Janeiro, pp. 184-200, dezembro 2002.

HOLANDA, Sérgio Buarque de. A herança colonial. Sua desagregação. In: HOLANDA, Sérgio Buarque de. História Geral da Civilização Brasileira. T. II, vol. I, 6 ed. São Paulo: DIFEL: 1985.

IGGERS, G. The Idea of Progress: A Critical Reassessment. The American Historical Review, Vol. 71, No. 1 (Oct., 1965), pp. 1-17. Disponível em: http://www.jstor.org/stable/1863033 Acesso em: 30/11/2009 11:45. 
KOSELLECK, Reinhart. Historia Magistra Vitae. Sobre la disolución del topos en el horizonte de la agitada historia moderna. In: __. Futuro Pasado: para una semántica de los tiempos históricos. Barcelona: Ediciones Paidós, 1993, pp. 41-66.

LALOUETTE, Jacqueline. Do exemplo à série: história da prosopografia. In: HEINZ, Flavio M. (org.). Por outra história das elites. Rio de Janeiro: Editora FGV, 2006, p. 55-74.

LISBOA, Bento da Silva; MONCORVO, José Domingues de Ataíde. Juizo sobre a obra intitulada "Histoire des rélations commerciales entre la France et le Brésil", par Horace Say. Revista do IHGB. 1:308-315, 1839; 3.ed. 250-255.

MALERBA, J. A Corte no Exílio: civilização e poder no Brasil às vésperas da Independência (1808-1821). São Paulo: Cia das Letras, 2000.

MALERBA, Jurandir. História, memória, historiografia: algumas considerações sobre história normativa e cognitiva no Brasil. ___ ROJAS, Carlos Aguirre (orgs.). Historiografia contemporânea em perspectiva crítica. Bauru, SP: Edusc, 2007, pp. 351-370.

NEVES, Lúcia Maria P. Intelectuais brasileiros nos oitocentos: a constituição de uma "família" sob a proteção do poder imperial (1821-1838). In: PRADO, Maria Emília (org.). O Estado como vocação: idéias e práticas no Brasil oitocentista. Rio de Janeiro: Access, 1999.

NISBET, R. História da idéia de progresso. Trad. De Leopoldo José Collor Jobim. Brasília: Ed. UNB, 1985.

PANTOJA, Gustavo Adolfo de Aguilar; VIANA, Cândido José de Araújo; PONTES, Rodrigo de Sousa da Silva. Juizo sobre a obra intitulada "Compendio das eras da provincia do Pará" por Antonio Ladislau Monteiro Baena, membro correspondente do Instituto. Revista do IHGB. 2:235-251, 1840; 3.ed. 242-258.

PANTOJA, Gustavo Adolfo de Aguilar; VIANA, Cândido José de Araújo; PONTES, Rodrigo de Sousa da Silva. Juizo sobre os "Annaes da provincia de São Pedro" 
publicados por José Feliciano Fernandes Pinheiro, Visconde de São Leopoldo. Revista do IHGB. 1:315-322, 1839; 3.ed. 255-260.

PINHEIRO, José Feliciano Fernandes. O Instituto Historico e Geographico Brazileiro é o representante das idéas de IIIustração, que em differentes épocas se manifestaram em o nosso continente. Revista do IHGB. T. 1, p. 65-85, 1839; 2.ed., p. 77-97; 3.ed., p. 6176.

PORTO ALEGRE, Manoel de Araujo. Discurso official do orador do Instituto o Sr. Manoel de Araujo Porto-Alegre. Sessão pública no dia 6 de abril de 1848 para inauguração dos bustos do cônego Januário da Cunha Barbosa e do marechal Raimundo José da Cunha Matos. Revista do IHGB. 11:215-288, 1848.

PORTO ALEGRE, Manuel de Araújo. Memória sobre a antiga Escola de Pintura Fluminense. Revista do IHGB. 3:547-557, 1841; supl. 33-43; 2.ed. 547-557; 3.ed. 451-458 REBELO, José Silvestre; REBELO, Lino Antônio. Juizo sobre a obra intitulada "Examen critique de l'histoire de la geographie du nouveau continent" par Alexandre Humboldt, membro honorario do Instituto. Revista do IHGB. 2:105-108, 1840; 2.ed. 105108; 3.ed. 105-108

REBELO, José Silvestre; REBELO, Lino Antônio. Juizo sobre a obra intitulada "Noticia descritiva da provincia do Rio Grande de São Pedro do Sul" por Nicolau Dreys. Revista do IHGB. 2:99-105, 1840; 2.ed. 99-105; 3.ed. 99-105.

SAID, Edward W. Representações do Intelectual. São Paulo, Companhia das Letras, 2005.

SCHWARCZ, L. M. A longa viagem da biblioteca dos reis. São Paulo: Cia das Letras, 2002. SCHWARCZ, Lilia Moritz. O Espetáculo das Raças: cientistas, instituições e questão racial no Brasil 1870-1930. São Paulo: Companhia das Letras, 1993. 
SHWEDER, R. A. On the Return of the 'Civilizing Project'. Daedalus, Vol. 131, No. 3, On

Education (Summer, 2002), pp. 117-121. Disponível em:

http://www.jstor.org/stable/20027795 Acesso em: 17/04/2010 13:46.

SIRINELLI, Jean-François. As elites culturais. In: RIOUX, Jean-Pierre; SIRINELLI, Jean-

François. Para uma história cultural. Lisboa: Estampa, 1998.

SIRINELLI, Jean-François. Os intelectuais. In: RÉMOND, René. Por uma história política. 2aㅡ ed. - Rio de Janeiro:Editora FGV, 2003.

VARNHAGEN, Francisco Adolpho de. Primeiro juizo....acerca do "Compendio da Historia do Brazil" pelo Sr. Jose de Abreu e Lima. Revista do IHGB. 6:60-83, 1844; 2.ed.60-83

VIANA, Cândido José de Araújo; PONTES, Rodrigo de Sousa da Silva. Juizo sobre a "Historia do Brazil" publicada em Paris pelo Sr. Dr. Francisco Solano Constâncio. Revista do IHGB. 1:91-6, 1839; 3.ed. 81-85.

WEHLING, Arno. A invenção da História: estudos sobre o historicismo. Rio de Janeiro: Editora Central da Universidade Game Filho; Niterói: Editora da Universidade Federal Fluminense, 1994.

WEHLING, Arno. As origens do Instituto Histórico e Geográfico Brasileiro. Revista do IHGB. V. 338, p. 7-16, jan./mar. 1983.

WEHLING, Arno. Estado, história, memória: Varnhagen e a construção da identidade nacional. Rio de Janeiro: Nova Fronteira, 1999.

WINOCK, Michel. O século dos intelectuais. Rio de Janeiro: Bertrand Brasil, 2000. 